\title{
IV COLOQUIO INTERNACIONAL DE TRADUCCIÓN MONACAL (Bolonia, 4 y 5 septiembre de 2017)
}

Los pasados días 4 y 5 de septiembre se celebró en la ciudad de Bolonia el IV Coloquio internacional de traducción monacal, organizado conjuntamente por la Facultad de Traducción de Soria de la Universidad de Valladolid (España) y el Dipartimento di Interpretazione e Traduzione de la Universitá di Bologna (Italia).

En el evento, patrocinado por el proyecto nacional I+D Catalogación y estudio de las traducciones de los dominicos españoles e iberoamericanos del ministerio español de Economía y Competitividad, y que llevó por título "Revelación y traducción en la Orden de los Predicadores", se dieron cita 37 investigadores de once países distintos (Alemania, Bélgica, Brasil, Costa Rica, Colombia, Chequia, China, España, Perú, Senegal y Tailandia) y de 16 universidades. Estuvo codirigido por el profesor Antonio Bueno (Universidad de Valladolid) y el profesor Rafael Lozano (Universidad de Bolonia), y fue inaugurado por el Rector de la Universidad de Bolonia. Contó con la participación de destacados investigadores como el doctor Iván Rodríguez Chávez (Rector de la Universidad Ricardo Palma, Lima), el doctor Hugo Marquant (Universidad de Lovaina), la doctora Jana Králová (Universidad Carolina) o el profesor Miguel Ángel Vega Cernuda (Universidad de Alicante).

Las ponencias de los participantes, que fueron retransmitidas de manera simultánea a través de Youtube y Facebook, abordaron cuestiones de interés como la labor de traducción e interpretación desempeñada por dominicos en las misiones del Nuevo Mundo, África y Asia, con atención a contextos específicos como Camboya, China, Chiapas, California, Senegal y muchos otros; sus aportaciones intelectuales y culturales en ámbitos como la mística, la filosofía, la retórica, la etnología, la hermenéutica, la lingüística o el aprendizaje de lenguas; su implicación en procesos históricos y culturales tan decisivos como el humanismo, la Inquisición y la Contrarreforma, la colonización, la transmisión activa del legado clásico y la articulación de la diferencia cultural, los debates confesionales y científicos de toda índole, sin desatender sus aristas más polémicas; las aportaciones específicas de centros regionales de la Orden como Alemania, Chequia o Perú; las repercusiones de sus trabajos en el cine, la arquitectura, el cómic, la fotografía, el folclore, la literatura y el arte en general.

De esta manera, el Coloquio sirvió para presentar un panorama amplio, matizado y diversificado de la significación cultural de la Orden, y cumplió con creces su propósito de servir como punto de encuentro científico en el que debatir y presentar los últimos avances sobre el conocimiento del valor y función de la labor de traducción de los religiosos a través de la historia.

Los resultados de investigación de este grupo internacional e interuniversitario son sorprendentes y ponen de manifiesto la importancia que para la cultura occidental ha supuesto la labor cultural del monacato. Los datos pueden ser consultados a través de la web y con libre acceso en: www.traduccion-monacal.uva.es. Hasta la fecha han logrado catalogar la actividad traductora y lexicográfica de las órdenes agustina, franciscana y dominicana, destacando en su catálogo casi dos mil traductores desde el siglo XIII a nuestros días con más de tres mil obras de referencia, además de 400 gramáticas y diccionarios y 80 lenguas, la mayoría indígenas de América, que no se habrían llegado a conocer sin las obras (artes, gramáticas y vocabularios esencialmente) de los misioneros.

Los primeros tres coloquios de este grupo de investigación dirigido por el profesor Antonio Bueno se celebraron en 2001 y 2005, en Soria y en 2011 en Asís (Italia), y estuvieron dedicados respectivamente a la labor monástica en general y de las órdenes agustina y franciscana en particular. En septiembre de 2016, en la localidad de Caleruega (Burgos), lugar de nacimiento de santo Domingo de Guzmán, tuvo lugar un coloquio internacional sobre la tarea intelectual y cultural de 
los dominicos, enmarcado dentro de los festejos con motivo del 800 aniversario de la fundación de la Orden. Es de esperar que en el futuro continúe la tarea de divulgación e investigación de un enclave imprescindible, si bien hasta ahora ampliamente desatendido, tanto de la historia de la disciplina traductológica como de nuestra tradición cultural.

por Cristian Camara Outes ${ }^{1}$ (Praga)

(Escrito en español por el autor) 